\title{
Hahnemann's Theory of Psora in the Light of Modern Science
}

\section{Ghosh AK}

The Jagaddal Noapara Homoeopathic Medical Association, West Bengal, India

*Corresponding author: Ghosh AK, Secretary, The Jagaddal Noapara Homoeopathic Medical Association, West Bengal, India, Tel: 9830983698; E-mail: mail.dr.ajoy@gmail.com

Rec date: Feb 13, 2015; Acc date: Mar 04, 2015; Pub date: Mar 07, 2015

Copyright: (c) 2015 Ghosh AK. This is an open-access article distributed under the terms of the Creative Commons Attribution License, which permits unrestricted use, distribution and reproduction in any medium, provided the original author and source are credited.

\begin{abstract}
Hahnemann observed that the non-venereal chronic diseases originate from a diseased condition or disposition to disease transferring from generation to generation for thousands of years. He named the diseased condition as Psora behaving as the fostering soil for almost all possible disease. According to Hahnemann Psora developed from suppression of itch disease by external application in ancient times. Hahnemann considered the peculiar cutaneous eruption was the outward manifestation of internal itch disease, the Psora. Therefore, any external treatment to remove the skin manifestation is detrimental to the patient and should be avoided. Some eminent dermatologist's perspicacious observation reveals that suppression of some kinds of skin diseases result in virulent internal disorder. It is again justified by another instance that under proper homoeopathic treatment of a chronic disease having history of suppressed skin manifestation in the past, the old eruption definitely reappear satisfying Dr. Hering's law of cure. Health is the result of the dynamic equilibrium among the disease agent, human host and the environment. Human host possessing hereditary factors have an immense role in the production of large number of diseases. Thus to bring cure to any disease especially chronic disease, one should focus one's attention towards the patient [host] to find out the fundamental cause without ignoring the disease agents and the environmental factors acting as exciting or maintaining cause. Hahnemann's 'Theory of Chronic Disease' serves as a pioneer to the key of ideal cure of innumerable chronic diseases. Until and unless, Miasm [the fundamental cause of all natural diseases] is done away with by dint of antimiasmatic treatment, the permanent cure of chronic disease is not possible.
\end{abstract}

Keywords: Non-venereal chronic diseases; Hahnemann's theory; Psora; Miasm.

\section{Introduction}

In the homoeopathic world "miasm" has raised a lot of controversy. Some stalwarts look upon it as a mere fantasy of Hahnemann and find no practical value of it in homoeopathic treatment. But others regard the theory of chronic miasm as the key to the achievement of homoeopathy in curing chronic disease. Treating natural diseases during thirty years by the homoeopathic method of treatment, Hahnemann perceived, the chronic diseases could not be perfectly cured by the simple similar medicines selected on the present symptoms associated with dietetic and hygienic measures and not even by vigorous, robust constitution. With passage of time the disease grew worse in addition to other more serious symptoms until the organism is fully destroyed. After thorough research to find out the cause behind the failure of similar remedies to cure the chronic diseases, Hahnemann noticed,---though the medicine prescribed, could subside the chronic disease for the time-being, yet the disease came back in a rather varied form with new symptoms. This led him to the conclusion that the presenting symptoms of a chronic disease represent merely the tip of a floating ice-berg. Hence, the original disease being deepseated, the whole history of chronic disease associated with accessory circumstances should be taken into consideration. Hahnemann also observed interestingly, the origin of most of the non-venereal chronic diseases lying in a peculiar type of skin eruption, frequently suppressed by a faulty practice. In spite of corroboration on his observation by some of the physicians of his time, most of them failed to accept any relation persisting between skin diseases and other diseases. However,
Hahnemann considered, the peculiar cutaneous eruption sometimes only of a few vesicles accompanied by intolerable voluptuous tickling itching was the outward manifestation of internal itch disease, the psora [1]

The word Psora originates from Hebrew word 'tsorat' meaning a groove or fault [2]. Hahnemann explained Psora as a diseased condition or disposition to disease transferring from generation to generation for thousands of years behaving as a fostering soil for almost every possible diseased condition. Psora, like other general diseases manifest outwardly only when, the whole economy has been completely affected. As the human skin does not evolve itself, without the co-operation of the rest of the living whole, it is irrational and thoughtless to consider any skin disease as merely the disease of the skin alone in which the internal portion of the organism takes no part. Therefore, any external treatment to remove the skin manifestation is detrimental to the patient and should be avoided [1]. With the progress of modern science, the skin disease thoroughly studied in association with other diseases, establishing the fact that the skin diseases are to be closely related to the other internal disorders.

\section{Controversy on Hahnemann's theory of chronic disease}

Publication of Hahnemann's book on chronic disease in 1828 brings forth a violent stir in the whole medical world. Very few books in the history of medicine produced so much controversy among the physicians. Even Barron Erust George Brunnow to whom Hahnemann had dedicated his work, was antagonistic to the view of Hahnemann regarding chronic diseases [3]. Hufeland [contemporary to Hahnemann] quoted, "At last the physician discovers that there is underlying, a hidden scabies or syphilis" [4]. In 1838, the Central 
Page 2 of 5

Congress of homoeopath in Frankfurt passed a resolution condemning the doctrine [5].

On the other hand many homoeopaths recognized the theory of chronic diseases as the most important discovery of Hahnemann. Stapf highly appreciated the book on chronic diseases as for its surprising explanations on the nature and treatment of chronic illness and emphasized to follow the doctrine strictly [6]. Boenninghausen and Hering, the staunch supporter of 'Psora theory' took it granted heartily [6].

After Hahnemann's expiry a number of homoeopathic stalwarts like Clarke [7], Stuart Close [8], Robert [9], Kent [10], O. Lesser [11] Von Grauvogl and others averred 'the doctrine of Psora is irrevocable' [12]. But a considerable number of homoeopathic physicians like Hering and Hughes are against Hahnemann's view regarding undue generalization in tracing all diseases to one primary disease-process [5].

Opinion of modern researchers: To keep pace with the progress of modern science various scientists carried on researches to unmask the mystery of 'Psora'. Stuart Close identified psoric miasm and Koch's tubercle bacilli were to be synonymous [8]. Mackenzie [13] has made an interesting attempt to substitute 'focal infection' for Psora, implying thereby the identification of the psoric miasms with strepto-staphylo and other pyogenic micro-organism. During researches in the Immunity School at University College Hospital, Dr. Edward Bach found that 'chronic intestinal organism lower general resistance, consequently local bacterial infections are almost certain to occur [14]. This ultimately makes a person susceptible to various diseases. He concluded that poisoning from certain organisms in the intestinal tract was the cause of chronic diseases and that on the removal of theses toxins the so-called chronic complaints disappear. Thus in his opinion, Psora and intestinal toxaemia were identical. Dr. Wheeler and Dr. Dishington also supported to Dr. Bach [14]. In 1926 Bach published his book 'Chronic Disease-A Working Hypothesis', written in collaboration with Dr. C.E. Wheeler of London, who had assisted him in his researches at London Homoeopathic Hospital. Dr. Paterson [15] of Glasgow, the well-known bacteriologist and homoeopath conducted a research work on bowel flora in the same line of Dr. Bach and demonstrated that the non-lactose fermenting organisms of the bowel are related to disease on the one hand, to the homoeopathic remedies on the other. His careful research revealed the same truth as Dr. Bach observed i.e. the patient's clinical condition and susceptibility depend on the change of his bowel flora. He declared, "In the treatment of chronic disease, it is near impossible to get successful results without a full knowledge of Hahnemannian doctrine of miasms." K. C. Chandran tried to analyze the concept of Miasms and Chronic disease in the light of scientific understanding of molecular biology [16]. Among others who have attempted to explain Hahnemann's theory of chronic disease, Bodman [17], Clignett [18], Eardley [19], Gordon Ross [20], Ross [21], Twentyman [22], Zissu [23], Ian Watson [24], Vithoulkas [25] are worth-mentioning.

\section{Reflection of emotion upon the skin}

The skin is the visible reflector of emotion and psychological disorder being just like a sensitive photographic plate on which emotional states such as anger by flushing, embarrassment by blushing and fear by paleness etc. are reflected.

Obermayer [26], on the basis of few clinical clues concludes that emotional problems are playing an important role in the genesis of any dermatitis. For example, pruritus is often utilized as a tension outlet. In atopic dermatitis, feeling of anger or guilt may be released through scratching. Urticaria can be an outlet for suppressed anger about unjust life situations. Rosacea may be a sign of the individual's feeling of inferiority and guilt in relation to handling problems arising at work. In hand dermatitis [dyshidrosis], vesiculation frequently follows anxiety situation within 24-28 hours. Psychiatric investigation of the more common dermatologic condition by Wittkower and Russel also coincides with Obermayer's view. Effective treatment may be obtained only by psychotherapy.

Emotional difficulties early in life lead to 'alopecia areata' of severe form where the scalp, beard and body hairs are involved. A 2-week time interval is apparently required for the development of alopecia areata following documentable trauma; this observation has been made in over 300 consecutive cases of alopecia areata, 20 of which have been reported in detail. Relief of emotional stress arrests further hair loss and within several months re-growth may occur. In case emotional problem persisting the disease progresses to alopecia totalis [entire head] or to alopecia universalis [entire body]. "In a 26 year old man alopecia areata developed four times during world war-II. The hair loss occurred each time within two weeks after he had participated in an island invasion in the south pacific. The hair regrew each time his unit was moved to a rest area between operations with permanent re-growth of all the hair at the end of the war" [27].

Griesmer [28] in his survey regarding the incidence of emotionally triggered dermatosis on 4,576 patients found that the eruption of about 34 percent was apparently precipitated by stress. The eczemas and acne clearly were not only very frequently seen, but also their exacerbation seemed to have occurred after stressful situations in over half the patients; atopic eczema and hand eczema seemed to have been emotionally triggered in three quarters of the cases. After the pioneer work of Alexender [29], a number of psychosomaticians tried to explain the pathogenesis of psychocutaneous diseases but still now the matters remain unsolved.

\section{Dermatosis due to internal diseases}

Numerous type of skin diseases are discussed, though the aetiology of most of them remains obscure. Genetic predisposition or morbid susceptibility for skin diseases plays an important role in its development like acne vulgaris, atopic dermatitis, psoriasis alopecia, vitiligo and many other conditions. Hahnemann concluded that Psora being manifested primarily as disease, any skin manifestation should not be taken into consideration with the skin only. This truth is focused in the light of modern science. In fact, skin as a mirror of health of a person, reflecting numerous internal disorders upon it. The manifestation of same type of skin disease may differ according to age and diathetic tendencies. A number of genetic and developmental abnormalities have both neurological and cutaneous manifestations most probably due to the common origin of the nervous system and the epidermis from the ectoderm. The skin is affected by malnutrition, whether caused by insufficiency, excessive demands, dietetic imbalance or mal absorption. It is also affected by endocrine and metabolic disturbances, including disordered activities of the pituitary, thyroid and para-thyroids, pancreas, suprarenal and gonads. Pruritus may occur in liver diseases, with or without jaundice, particularly in billiary cirrhosis. Chronic renal disease with uraemia may cause general pruritus and a light brown diffuse pigmentation of the skin. Diabetes mellitus may be associated with infection include boils, carbuncles, ulcers, gangrene, tinea of the feet and the groin and 
Page 3 of 5

infectious eczematous dermatitis. Asthma may alternate with attacks of Urticaria or may co-exist with it.

Therefore modern medical science unveils Hahnemann's idea that no external application but internal medicine essentially requires to cure skin manifestation due to internal diseases.

\section{Adverse effects of suppression of skin disease by external application}

In confirming with his own view Hahnemann in his book 'Chronic Diseases', gave an account of a cases of experiences of the writers in all centuries regarding the injurious effects[sever bodily or mental sufferings] of suppressed eruption [30].

Some eminent dermatologist's perspicacious observation reveals that suppression of some kinds of skin diseases result in virulent internal disorder and occasional death ultimately.

According to Brocq [31] the rapid disappearance of an eczematous eruption in a young child may be followed by pulmonary congestions of the most dangerous kind (Atopic march). He observed also that it is especially in middle life that alternations between eczematous lesions on the skin and visceral manifestations of greater or less gravity [pulmonary, renal, intestinal, cardiac, cerebral etc.] are most likely to show themselves.

Sir Morris [32] observed eczema which appears at puberty alternates with neurotic conditions, more especially with asthma and commencing osteoarthritis. He noted that the irritation of the skin may, as pointed out by Kaposi, set up reflex irritation in the intestine, preventing the proper digestion of food. The irregularities of the bowels react in turn on the skin, and thus a vicious cycle is established. The most common intestinal complication of skin diseases is dyspepsia. Gout is also a frequent complication.

A too rapid cure of eczema in children or its spontaneous disappearance may produce grave metastasis like bronchitis, dysenteric enteritis or pulmonary congestion, sometimes followed by death. In adults especially in old people, the disappearance of generalized eczema may be followed by the same accidents or by other manifestations such as asthma, rheumatism etc. These metastasis also occur in other dermatitis than eczema; prurigo may alternates with bronchitis; psoriasis with rheumatism, dyspnoea etc. [33].

Chronic suffering from rosacea may produce eye lesions, such as keratitis, conjunctivitis and blepharitis. Atopic eczema is one manifestation of a triad of atopic conditions the other two being bronchial asthma and hay fever [34].

Application of corticosteroids, topically and systematically in atopic dermatitis causes severe complication such as cataracts causing blindness [35].

In sub-acute and chronic eczema success often depends more on the dermatologist's understanding of the patient's personality, social domestic conditions and ability to carry out the treatment satisfactorily than on the choice of topical application. For contact dermatitis all hand creams or lotions should be forbidden [36].

Substances which are poorly absorbed through intact skin may penetrate diseased skin freely. So any substance used for topical application in skin disease produces serious systemic effects [37].

It is observed by the physicians that there is a relationship between eczema and asthma. According to BBC NEWS, scientists believe that they have found what triggers many children with eczema to go on to develop asthma. The US team at the Washington University School of Medicine showed that a substance made by the damaged skin triggered asthma symptoms in mice. The same substance, thymic stromal lymphopoietin [TSLP] is also produced in the lungs of asthma patients. Early treatment of the skin rash and blocking TSLP production might stop asthma developing in young patients with eczema, they hope. Drugs that act on TSLP might also protect against asthma developing even in cases that are not linked to eczema [38]. It is estimated that more than six million Australians have suffered from eczema at some stage of their lives - and more than $90 \%$ developed this condition before their fifth birthday. Medical experts have long been mystified by way so many eczema sufferers also develop asthma and allergies - what they call the atopic march. Studies show that $50-60 \%$ of children with severe eczema go on to develop childhood asthma. It has shown that a substance secreted by damaged and broken skin (caused by the itchy eczema) moves through the body and can trigger asthmatic symptoms. These findings suggest that the early treatment and control of skin rashes caused by eczema may stop asthma developing [39]

Eczema and asthma are closely related by the reason that both may have similar pathogenic mechanism underlying their manifestations. Both are due to the effect of hypersensitivity reactions which are mediated by IgE Antibody affixed to the surface of mast cells and basophiles, and both can be triggered by exposure to allergens [40-42].

Hahnemann's theory is again justified by another instance that under proper homoeopathic treatment of a chronic disease having history of suppressed skin manifestation in the past, the old eruption definitely reappear satisfying Herring's law of cure. This incidence comes to be every day phenomenon found in any homoeopathic clinic, hospital or health centre. The distinguished homoeopathic physicians mentioned their own cases in their books. If we go through the case records from the respective books, we can see that in a considerable number of cases, the Hering's Law of Cure can be verified. For quick references a few interesting cases are shown here in a nut shell.

Dr. P. Sankaran mentioned a case in his book 'The Pathology in Homoeopathy'. A three year-old boy had an ulcer on his lips. The diagnosis was 'cancrum oris'. Sulphonamide ointment was applied on the affected parts. Ulcer disappeared in no time, but left a black patch on the lips. After a couple of months the black spot also vanished. Some days after this incident, mental abnormality was perceived in the behavior of the boy. After four years the boy was taken to Dr. Sankaran . Doctor prescribed a selected homoeopathic medicine and the boy recovered. Mental problem was gone but the old ulcer of the lips reappeared. Then the ulcer was treated by homoeopathic method. The result was that the boy remained well in mind as well as in the skin [43].

Carrol Dunham, in the book, 'Science of Therapeutics', recorded a case of deafness caused by suppressed Psora. Dunham treated a seventeen year old young man for his hearing trouble which started when he was four years of age. Past history revealed that at the age of three he suffered from eczema of thick, whitish scabs, hard, almost horny, covering the whole scalp. The eruption was suppressed by external application. From that time the child faced the problem of hearing. Dunham prescribed not for direct deafness. He selected homoeopathic medicine Mezerium on the basis of skin eruption which remained in the past. The deafness was completely cured [44]. 
Page 4 of 5

Nash noted an interesting case in his book 'Leaders in Homoeopathic Therapeutics'. Dr. Nash treated a lady suffering from Gastritis. She became skeleton-like. Nash found after much questioning that about fifteen years ago' she had eczema on the nape and occiput. The eczema was suppressed by the application ointment. Dr.Nash prescribed Sulphur 200th. Her stomach trouble completely removed but the eruption reappeared [45].

Dr. Nash mentioned another case. He treated a case of very severe gastralgia caused by suppression of eczema on the hands. Dr. Nash prescribed Arsenicum because the pain came on at midnight, lasting until 3 A.M. during which time the patient had to walk the floor in agony, and there was great burning in stomach. She had but one slight attack after taking Arsenicum but old suppressed eczema came back [45].

Dr. S. P. Dey of Calcutta noted a case in his book, 'Clinical Case Reports on Constitutional Prescribing'. He treated a student aged 19 years, suffering from Rheumatoid Arthritis. He had skin disease in childhood. The eruption was suppressed by local application of ointments. Considering the totality of the symptoms of the case, Dr. Dey prescribed Medorrhinum $1 \mathrm{M}$. The patient's condition was remarkably improved. But three months later there was severe aggravation of the old skin condition. Through constitutional treatment for one year, the patient was cured. He had no pain anywhere no skin symptom [46].

To my own interest, when I had been house surgeon of D. N. De Homoeopathic Medical College Kolkata I had gone through the old case record books of indoor departments thereof. It was interestingly observed that a fair number of patients suffering from chronic diseases gave the history of suppression of skin disease in the past.

Total number of cases recorded in one year was 266. Out of them, history of suppression of skin disease of 110 patients was found. Among 266 total cases 72 patients were of Asthma of which 56 patients had a history of suppressed skin disease (mainly eczema); 58 patients were of Gastritis of which 22 patients gave history of suppression of skin disease (mainly scabies); 25 cases were of Kidney dysfunction of which 8 persons had suppressed skin ailments (either psoriasis or eczema); 84 cases exhibited Rheumatoid Arthritis of which 12 patients revealed as past suppression of psoriasis; 28 cases were of Cardio Vascular Disease of which only 2 were found of suppression of skin disease (Tables 1 and 2).

\begin{tabular}{|l|l|l|l|}
\hline Name of Hospital & Total number of cases in one year & $\begin{array}{l}\text { History of suppression of skin } \\
\text { disease in the past }\end{array}$ & Percentage (\%) \\
\hline $\begin{array}{l}\text { D. N. De Homoeopathic Medical } \\
\text { college and Hospital Calcutta. }\end{array}$ & 266 & 110 & 41.4 \\
\hline
\end{tabular}

Table 1: Percentage of cases, revealed history of suppressed skin disease in the past in respect to total number of cases treated in one year.

\begin{tabular}{|l|l|l|l|}
\hline Type of diseases & Total number of cases & $\begin{array}{l}\text { History of suppression of skin } \\
\text { disease in the past }\end{array}$ & Percentage (\%) \\
\hline Asthma & 72 & $56($ eczema,48 and others,8) & 76.66 \\
\hline Gastritis & 58 & 22 (scabies, 18 and others,4) & 38 \\
\hline Kidney disorder & 24 & 8 ( psoriasis,5 and eczema,3) & 33.33 \\
\hline Rheumatoid Arthritis & 84 & 12 (psoriasis, 9 and other 3) & 14.25 \\
\hline Cardio Vascular Diseases & 28 & 2 (eruption, allergic) & 7.14 \\
\hline
\end{tabular}

Table 2: Percentage of different type of diseases, influenced by suppression of skin disease in the past.

\section{Conclusion}

Hahnemann considered Psora as a disease or disposition to disease transmitted from generation to generation for thousands of years. Health is the result of the dynamic equilibrium among the disease agent, human host and the environment. The latest conception about the causation of disease reveals clearly that disease is due to the effect of 'multiple factors' those are directly or indirectly related to the agent, host and environment, viz., biological, nutrient, chemical, physical, mechanical, psycho-social, cultural, hereditary factors etc. According to recent opinion, the hereditary factors among these are the most predominant or fundamental cause as Hahnemann had indicated [47]. Refuting the former belief of hereditary factors in playing a role in the causation of only of a few chronic diseases, it is established that they have an immense role in the production of large number of diseases. Evidently in case of epidemic or endemic diseases, we find a variable susceptibility in the human population remaining the same risk factors to viral, bacterial or parasitic infections. Studies on twins [both identical and non-identical] indicate that heredity is partly responsible for various forms of insanity, for cancer and for other human disorders. Most tumour biologists believe that there are multiple mechanisms that influence the growth and spread of cells transformed to the neoplastic state and that most of them are, in a broad sense, genetically influenced. Diabetes mellitus, obesity, gout, essential hypertension, peptic ulcer, cancer, neuroses, psychoses, mental retardation, many infectious diseases such as acute rheumatic fever and tuberculosis are few examples where hereditary predisposition plays an important part. Therefore to bring cure to any disease especially chronic disease, one should focus one's attention towards the patient [host] to find out the fundamental cause without ignoring the disease agents and the environmental factors acting as exciting or maintaining causes.

Hahnemann's theory of Psora was very simple as it was based on practical observations. Hahnemann standing on the basement of his power of his perfect observation and foresight, perceived the close 
Page 5 of 5

connection lying between skin and rest of the body. What Hahnemann emphasized in his Psora theory that the serious complication might develop from suppression of skin disease is no longer denied by modern science. It's not the only efficacy of Psora theory, but it serves as a pioneer to the key of ideal cure of innumerable non venereal chronic diseases. In treatment of chronic diseases, to achieve success by means of homoeopathic method, there is need of proper 'Anti Miasmatic' treatment. Hahnemann opines that the fundamental cause of all natural diseases is the Miasm. Until and unless, Miasm is done away with by dint of Anti Miasmatic treatment, the permanent cure of chronic disease is a far cry. According to Hahnemann's 'Psora Theory', Psora is the mother of almost all chronic diseases. Consequently in some of the stages of treatment of any type of chronic disease, it is necessary to bring Psora under control. Anti Psoric remedies are selected according to the general principles of homoeopathy. It is administered one dose at a time, the effect of which as a rule allowed passing away completely before being repeated. Over hasty repetition of anti-psoric remedies is to be avoided as much as the employment of too large doses. Dr. J. H. Allen, the author of 'The Chronic Miasms Psora and Pseudo-Psora', concluded, "we cannot select the most similar remedy possible unless we understand the phenomenon of the acting and basic miasms; for the true similar is always based upon the basic miasm, whether we be conscious or unconscious of the fact."

Therefore Hahnemann's 'Theory of Chronic Disease' should be perceived and it must be implemented in practical field so that a physician may achieve his mission i.e. "to restore the sick to health to cure."

\section{References}

1. Samuel H (1981) The Chronic Diseases: Their Peculiar Nature and Their Homoeopathic Cure New Delhi: Jain publishing Co. Vol: 1.

2. Roberts HA (1976) The Principles and Art of Cure by Homoeopathy. New Delhi: B. Jain publishers, p. 184.

3. Richard H (1993) Samuel Hahnemann His Life \& Work. New Delhi: B. Jain publishers, p. 149

4. Richard H (1992) Samuel Hahnemann His Life \& Work. New Delhi: B Jain publishers, Vol. II., Reprinted in India, p. 167.

5. Sankaran P (1961) Pathology in homoeopathy: A New Look at Chronic Diseases. Santa Cruz Bombey-54: The Homoeopathic Medical Publishers, p. 39.

6. Richard H (1992) Samuel Hahnemann His Life \& Work. p. 177.

7. Clarke JH. The Prescriber The Homoeopathic Publishing Co. p. 29.

8. Stuart C (1979) The Genius of Homoeopathy: 'The Identity of Psora and Tuberculosis' New Delhi: B. Jain publishers p. 102.

9. Roberts HA (1976) The Principles and Art of Cure by Homoeopathy. New Delhi: B. Jain publishers p. 182.

10. Kent JT (1977) Lectures on Homoeopathic Philosophy. New Delhi: B. Jain publishers, p. 137.

11. Lesser O Text Book of Homoeopathic Materia Medica.

12. Richard H (1992) Samuel Hahnemann His Life \& Work. New Delhi: B. Jain publisher, p. 168.

13. Mackenzie (1933) Journal of the American Institute of Homoeopathy, p. 716.

14. Bach Edward Chronic Disease-A Working Hypothesis.

15. Patersion J (1950) The Bowel Nosodes. Brit. Hom. J.
16. Chandran KC (2013) Miasms: Understanding Its Biological Mechanism, Homoeopathy Articles.

17. Bodman FH (1939) Constitutions and Chronnic Disease, Brit Hom J, p. 224.

18. Clignett PO (1965) Natural Defenses against viruses, Brit Hom J, p. 239.

19. Eardley AWR (1962) Heredity and Homoeopathy, Brit Hom J, p. 68.

20. Gordon Ross AC (1962) Chronic Disease, Brit Hom J, p. 84.

21. Ross TD (1962) Miasmatic thoughts: Brit Hom J, p. 71.

22. Twentyman LR (1952) Miasms and Archetypes, Brit. Hom. J. 42: 130.

23. Zissu Roland (1961) The evolution of Ideas on Constitution and Temperament from the Homoeopathic Standpoint, Brit. Hom. J. pp: 50-55.

24. Watson Ian. The Homoeopathic Miasm-A Modern View. eBook Amazon.co.uk

25. Vithoulkas George (2002) The Science of Homoeopathy New Delhi: B. Jain publishers.

26. Obermayer M (1955): Psychocutaneous Medicine. Spring field, III.

27. Thomas B. Fitzapatrick, Arthur Z.Eisen, Irwin M, Fredberg K (1979) Dermatology in General Medicine New York: McGraw-Hill Co. p. 1358

28. Griesemer RD (1978) The incidence of emotionally triggered disease in dermatologic practice, Psychiartr Ann 8: 49-56.

29. Alexander F, French TM, Pollock GH (1968) Psychosomatic specificity. Chicago: Univ. of Chicago Press p. 4-11.

30. Hahnemann Samuel (1981) The Chronic Diseases, Their Peculiar Nature and Their Homoeopathic Cure New Delhi: Jain India publishing Co. p. 18-31.

31. William Wood and Co. (1909) Moris Sir Malcolm: Diseases of the skin. New York.

32. William Wood and Co. (1908) Moris Sir Malcolm: Diseases of the skin. New York.

33. Gaucher, Earnest (1910) Diseases of the skin, including radiotherapy and radium therapy. London: John Murray Publishing House. p. 11.

34. Gordon C (1982) Sauer: Manual of skin diseases, Lippincott Williams, (4thedn) p. 223-225.

35. Wyngarden James B (1982) Cecil Text Book of Medicine Elsevier. Health Science Division 2: 2271.

36. Arthur Rook, Wikinson DS, Ebling FJG (1982) Text Book of Dermatology London: Black Well Science Ltd. (3rdedn) p. 306.

37. Arthur Rook, Wikinson DS, Ebling FJG (1982) Text Book of Dermatology London: Black Well Science Ltd. (3rdedn) p. 144.

38. BBC NEWS (2009)Eczema's link to asthma uncovered.

39. Eczema and asthma: the link (2010) kidspot.

40. Atkinson F (2009) Middleton's allergy: Principle and Practice (7thedn).

41. Holgate S, Lamnske R, Simson (2009) FER Publisher Mosby, an affiliate of Elsevier, Inc.

42. Leslie C (2009) Grammar and Greenberger Paul A. Patterson's Allergic Diseases, Philadelphia: Lippincott Williams \& Wikins, (7thedn).

43. Sankaran P (1961) Pathology in homoeopathy. Santa Cruz, Bombey-54, The Homoeopathic Medical Publishers pp: 18.

44. John Henry C (1983) A Dictionary of Practical Materia Medica, New Delhi: Jain publishing Co. p. 482.

45. Nash EB (1959) 'Leaders in Homoeopathic Therapeutics' Set Dey \& Co. p. 89.

46. Dey SP (1979) Clinical Case Reports on Constitutional Prescribing C. Ringer \& Co.

47. Skamene Emil (1980) Genetic Control of Natural Resistance to Infection \& Malignancy. Elsevier Inc. 